\title{
ANALISIS EVALUASI KESESUAIAN LAHAN EKOWISATA BLOK MANGROVE BEDUL KABUPATEN BANYUWANGI
}

\author{
Bigharta Bekti Susetyo ${ }^{1}$, Sudarno Herlambang ${ }^{2}$, dan I Komang Astina ${ }^{3}$ \\ E-mail: bighartabekti@yahoo.com, sudarno.herlambang.fis@um.ac.id, \\ komang.astina.fis@um.ac.id
}

\begin{abstract}
Abstrak: Penelitian ini bertujuan untuk mendiskripsikan kesesuaian lahan Ekowisata Mangrove Bedul di stasiun penelitian A, B dan C serta kesesuaian lahan ekowisata dengan penggunaan lahan di Ekowisata Mangrove Bedul. Jenis penelitian ini adalah penelitian deskriptif kuantitatif dengan metode survei lapangan. Penentuan titik stasiun penelitian menggunakan metode purposive dengan metode plot dan transek garis. Analisis data menggunakan analisis deskriptif kuantitatif dengan scoring. Hasilnya penelitian ini menunjukkan (1) Stasiun penelitian A, B dan C memiliki kesesuaian lahane kowisata yang berbeda. Stasiun A memiliki nilai 17 (sangat sesuai), stasiun B memiliki nilai 20 (sangat sesuai) dan stasiun $\mathrm{C}$ memiliki nilai 16 (Cukup sesuai). (2) Penggunaan lahan di Ekowisata mangrove Bedul didominasi oleh tipe mangrove sungai dan muara yaitu jenis Avecennia, Lumnitcera, Brugruiera, Ceriops dan Sonneratia.
\end{abstract}

Kata Kunci: kesesuaian lahan, mangrove, ekowisata

\section{PENDAHULUAN}

Kegiatan pariwisata yang beragam membuat manusia berupaya memfaatkan satuan lahan yang ada agar kegiatan pariwisata dapat optimal. Melalui evaluasi lahan dapat didahului dengan penilaian terhadap kemampuan lahan, yakni memberikan penilaian pada parameter-parameter lahan untuk tujuan kepariwisataan (Widyanto dan Dibyo Saputro, 1991:15). Parameter yang digunakan untuk mengetahui daya dukung satuan lahan yang digunakan untuk maksud tertentu.

Mangrove Bedul yang berada di Desa Sumberasri, Kecamatan Purwoharjo merupakan mangrove terluas di Pulau Jawa (TN Alas Purwo). Mangrove Bedul dengan luas $2300 \mathrm{Ha}$ memiliki fungsi penting (Nugroho, 2011:204). Berbagai

\footnotetext{
${ }^{1}$ Mahasiswa Jurusan Geografi UM

${ }^{2}$ Dosen Jurusan Geografi UM

${ }^{3}$ Dosen Jurusan Geografi UM
}

fungsi penting hutan mangrove dirasakan secara langsung maupun tidak langsung oleh manusia diantaranya fungsi fisik, biologis, kimia dan ekonomi (Arief, 2001:42). Pemanfaatan lahan pada ekosistem mangrove rawan mengalami degradasi lahan yang mempengaruhi kelestarian alam.

Keinginan warga dan pemerintah desa untuk memaksimalkan kegiatan ekowisata di Blok Mangrove Bedul perlu mendapatkan ijin dari instansi Taman Nasional Alas Purwo. Ijin yang diusahakan berupa pembuatan akses jalan menuju objek lokasi ekowisata dan perubahan penggunaan lahan, yang sebenarnya hutan lindung menjadi hutan dengan pengelolaan dan penambahan pendukung kegiatan ekowisata. Pada 
tahun 2007 terealisasi kesepakatan antara pihak Desa Sumberasri dengan pengelola Taman Nasional Alas Purwo tentang pengelolaan Blok Mangrove Bedul sebagai daerah yang dimanfaatkan sebagai pariwisata yang berbasis lingkungan.

Aktivitas manusia yang intens saat kegiatan ekowisata pada lahan mangrove perlu adanya pengelolaan yang tepat. Pemanfaatan lahan mangrove dalam kegiatan ekowisata diharapkan tetap lestari dengan evaluasi kondisi lahan mangrove sebagai salah satu strategi pengelolaan mengamankan, mempelajari dan memanfaatkan ekosistem mangrove (Arief, 2001:43). Pemanfaatan mangrove secara fisik, ekonomi, biologis, dan kimia perlu dibatasi dengan pengelolaan yang tepat.

\section{METODE}

Penelitian ini merupakan penelitian deskripstif kuantitanif dengan metode survei. Penelitian ini mendiskripsikan tingkat kesesuaian lahan Ekowisata Blok Mangrove Bedul. Data dalam penelitian ini berupa data primer dan data sekunder. Pengukuran lapangan mengunakan metode purposive dengan teknik plot transek dan garisuntuk menentukan tiga stasiun pengukuran. Setiap stasiun penelitian memiliki tiga plot yang masing-masing berukuran 10x10 meter.

Pengumpulan data dilakukan dengan dokumentasi, observasi, dan pengukuran lapangan. Data primer meliputi, $\mathrm{pH}$ pori air, salinitas, bahan organik, tekstur tanah, dan vegetasi mangrove diperoleh dari pengukuran lapangan. Data sekunder meliputi biota, kondisi pasang surut dan vegetasi mangrove. Data yang terkumpul dianalisis menggunakan teknik scoring, dan hasil scoring tersebut diklasifikasikan berdasarkan parameter kesesuaian lahan ekowisata. Peta kesesuaian lahan ekowisata mangrove merupakan hasil dari penelitian di Ekowisata Blok Mangrove Bedul.

\section{HASIL DAN PEMBAHASAN}

Letak astronomis Desa Sumberasri pada $8^{0} 31^{\prime} 48^{\prime \prime}$ LS - 8 $36^{\prime} 18^{\prime \prime}$ LS dan $114^{0}$ $15^{\prime}$ - $114^{0} 17^{\prime} 27^{\prime}$ '. Letak administrative Desa Sumberasri berada pada Kecamatan Purwoharjo. Desa Sumberasri adalah desa terluas dalam Kecamatan Purwoharjo. Desa Sumberasri memiliki luas wilayah $1082 \mathrm{~m}^{2}$ atau $59,71 \%$ dari luas total Kecamatan Purwoharjo. Desa Sumberasri terdiri dari empat dusun yaitu Dusun Krajan, Blok Solo, Kedung Kandel dan Sumber Rejeki.

Mangrove Bedul memiliki luas sekitar 1200 Ha. Luas Mangrove Bedul terdapat dalam wilayah administrative Desa Sumberasri, Desa Grajagan dan Kecamatan Tegaldlimo. Luas vegetasi Mangrove Bedul yang berada pada Desa Sumberasri memiliki luas $56 \mathrm{Ha}$ (Profil Desa Sumberasri, 2013). Berikut lokasi penelitian kesesuaian lahan Ekowisata Mangrove Bedul.

Berdasarkan hasil penelitian di lapangan, selanjutnya menetapkan nilai indeks kesesuaian lahan ekowisata. Stasiun pengukuran memperoleh nilai atau kategori sesuai indeks ekowisata mangrove. Indeks kesesuaian lahannya dapat dilihat pada tabel di bawah ini. 
Total kesesuaian lahan Ekowisata Mangrove Bedul Stasiun A memiliki nilai 17. Kondisi mangrove Stasiun A memiliki kategori sangat sesuai (highly suitable). Kategori lahan stasiun A tergolong sesuai. Lahan dataran aluvial pantai memiliki kondisi lingkungan yang sesuai dan mendukung untuk keperluan pariwisata. Kemampuan alamiah untuk penggunaan lahan tahunan termasuk tinggi dengan satu aktivitas atau lebih secara instensif.

Total kesesuaian lahan Ekowisata Mangrove Bedul Stasiun B memiliki nilai 20. Kategori kesesesuaian ekowisata mangrove stasiun B sangat sesuai (highly suitable). Pada kelas kesesuaian ini, mempunyai kondisi lahan yang sesuai. Lahan dataran aluvial pantai memiliki kondisi lingkungan yang sesuai dan mendukung untuk keperluan pariwisata. Kemampuan alamiah untuk penggunaan lahan tahunan termasuk tinggi dengan satu aktivitas atau lebih secara instensif.

Total kesesuaian lahan Ekowisata Mangrove Bedul Stasiun C memiliki nilai 16. Kategori kesesesuaian ekowisata mangrove stasiun $\mathrm{C}$ cukup sesuai (quite suitable). Lahan pada kelas ini memiliki kemampuan sedang untuk keperluan pariwisata. Kemampuan secara alamiah untuk penggunaan lahan tahunan termasuk sedang dari aktivitas yang umumnya terpencar. Lahan mempunyai kondisi yang baik dengan kekurangan yang masih bisa untuk diupayakan keperluan pariwisata.

Ekowisata Mangrove Bedul terletak pada dataran Aluvial pantai. Daerah Aluvial pantai merupakan daerah dari hasil bentuk lahan marin. Pada daerah muara sungai, daerah aluvial pantai berhubungan dengan proses fluvial. Proses marin dan fluvial pada muara sungai biasanya terbentuk oleh daerahdaerah penimbunan (Widyanto dan Dibyosaputro, 1991:25).

Daerah penimbunan dipengaruhi oleh gerakan air dan angin yang berkontribusi terhadap terbentuknya dataran aluvial sampai laguna. Drainase tanah permukaan adalah kumpulan dan perpindahan air dari permukaan tanah (Foth, 97: 1984). Drainase permukaan dipengaruhi oleh dua faktor. Area yang landai menerima air dari daerah yang lebih tinggi dan kapasitas tanah impermeabel yang cukup untuk membuang kelebihan air dengan resapan melalui profil tanah (Foth, 97: 1984).

Kondisi drainase tanah diketahui melalui warna tanah (Jamulya dan Sunarto, 1991:33). Kondisi drainase tanah yang baik akan mempunyai warna tanah yang seragam. Warna tanah seragam adalah warna tanah yang tidak ada bercak-bercak kuning atau kelabu. Kondisi tanah yang memiliki warna yang seragam memiliki aerasi yang baik untuk kondisi perakaran vegetasi.

Kondisi drainase tanah pengukuran di Mangrove Bedul memiliki criteria sesuai dancukup sesuai. Pada stasiun A dan $\mathrm{C}$ mempunyai warna tanah yang seragam sedikit bercak-bercak kuning. Pada stasiun B mempunyai warna tanah yang seragam tidak ada bercak-bercak kuning dan kelabu.

Bagian penting drainase tanah hutan mangrove adalah kedalaman muka air yang rendah dalam kedalaman efektif akar (Footh, 1984: 96). Kondisi drainase 
pada ekosistem mangrove berkaitan dengan keadaan aerasi dan kemampuan air dalam menerobos perakaran. Vegetasi mangrove akan tumbuh baik jika didukung oleh kondisi aerasi dan porositas yang baik. Kondisi drainase tanah yang baik mempengaruhi keadaan water table di dalam tanah. Air dapat menorobos dan mengubah keadaan water table yang bisa lebih dekat dengan permukaan tanah yang memudahkan akar vegetasi mangrove untuk menjangkau air tanah.

Kedalaman muka air tanah diketahui berdasarkan pengukuran muka air tanah dari sumur. Pengukuran menggunakan tali dengan pemberat sampai dasar sumur kemudian mengukur selisih ketinggian bangunan sumur. Kedalaman muka air tanah berkaitan ketersediaan air untuk akar mangrove. Kedalaman muka air tanah yang dangkal mempermudah akar vegetasi mangrove untuk menjangkau air tanah. Kedalaman muka air tanah memiliki peranan dalam ekowisata. Akses air bersih kepada ekowisatawan menjadi kebutuhan yang wajib. Kondisi muka air tanah yang dangkal membuat pengelola membangun fasilitas air bersih dalam kegiatan ekowisata dengan lebih mudah (Pangesti, 2007).

Jarak lokasi sumur dari masingmasing stasiun pengukuran berbeda. Jarak lokasi sumur dengan stasiun A tercatat 426 meter yang memiliki skor 3 (sangat sesuai). Jarak lokasi sumur dengan stasiun B tercatat 512 meter yang memiliki skor 2 (cukup sesuai). Jarak terjauh dari sumur adalah stasiun $\mathrm{C}$ yang tercatat 1197 meter yang memiliki skor 1 (sesuai bersyarat).
Jarak lokasi sumur dengan kegiatan ekowisata berkaitan dengan aksesbilitas. Kegiatan ekowisata memerlukan air bersih yang dapat digunakan untuk mandi, cuci dan kakus. Jarak yang jauh akan mempengaruhi keterjangkauan ekowisatawan yang hendak memerlukan akses terhadap ketersediaan air bersih (Pangesti, 2007).

Salinitas air laut marupakan tanda keadaan kondisi air pada lingkungan mangrove. Salinitas air laut dalam lingkungan ekosistem mangrove dipengaruhi oleh letak ekosistem mangrove yang berada pada estuari atau sempadan sungai yang dipengaruhi oleh air laut. Air laut dapat mempengaruhi kehidupan mangrove yang memiliki toleransi terhadap tingkat salinitas tertentu agar dapat tumbuh optimal.

Pada tiga stasiun pengukuran, kondisi salinitas ekosistem mangrove baik. Kondisi salinitas pada tiga stasiun pengukuran memiliki skor tinggi dan sesuai dengan tumbuh vegetasi mangrove diantara $0,15 \%$ sampai $3 \%$. Pada stasiun A memiliki salinitas $1,65 \%$ merupakan salinitas terbesar dari tiga stasiun pengukuran.

Ekosistem mangrove dapat tumbuh pada salinitas air payau dan air asin 0,015\%-5\% (Bengen, dalam Fahriansah dan Yoswati, 2012) . Kondisi salinitas pada ekosistem mangrove estuari mempunyai pengaruh salinitas yang kompleks. Kondisi salinitas pada daerah muara dipengaruhi oleh pertemuan antara air tawar yang relatif ringan, air laut yang lebih berat dan sirkulasi air di muara sungai (Nontji, 1987:60).

$\mathrm{pH}$ pori air merupakan tingkat $\mathrm{pH}$ pada pori-pori air yang terdapat pada 
sekitar lingkungan mangrove. $\mathrm{pH}$ air pada pori-pori mangrove diukur untuk mengetahui kondisi air pada lingkungan ekosistem mangrove yang mampu tumbuh optimal pada $\mathrm{pH}$ yang berkisar pada 7-8,5 (Kepmen No.51/MENKLH /2004).

$\mathrm{pH}$ pori air pada lingkungan Mangrove bedul memiliki rata-rata $\mathrm{pH}$ berkisar 7. Keadaan $\mathrm{pH}$ pori air yang berkisar bernilai 7 menjadikan vegetasi mangrove memiliki keadaan optimal untuk tumbuh. Keadaan optimal untuk tumbuh berhubungan dengan tutupan lahan mangrove. Ekowisata mangrove yang memiliki tutupan lahan yang lebat dan keragaman jenis yang banyak menambah daya saing ekowisata. Kadar bahan organik sedimen yang tinggi memiliki peranan yang penting. Peranan kadar bahan organik sedimen terkait dengan penguraian unsur hara lahan. Unsur tekstur dan drainase tanah yang baik selaras dengan proses penguraian bahan organik yang baik pula. Kadar bahan organik akan terbentuk oleh aktivitas mikroba dalam tanah yang mempunyai drainase tanah baik (Tangketasik dkk, 2012:101).

Bahan organik sedimen pada masing-masing stasiun berbeda. Pada stasiun A kadar bahan organik sebesar $0,51 \%$. Kadar bahan organik pada stasiun B sebesar 3,48 \%. Kadar bahan organik pada stasiun C sebesar 3, $29 \%$. Kadar bahan organik sedimen pada tiga stasiun pengukuran memiliki kadar bahan organik yang tinggi.

Prokduktifitas tanah yang baik memiliki bahan organik tanah yang cukup. Bahan organik tanah yang rendah memiliki berpengaruh dalam penurunan produktivitas tanah (Juarti, 2004:6). Bahan organik yang rendah pengaruhi oleh erosi dan pembentukan hara yang tidak optimal. Pada stasiun B dan C memiliki kondisi drainase yang baik dan mempunyai produktivitas tanah yang baik.

Bahan organik memiliki kaitan dengan tekstur tanah. Bahan organik yang rendah pada stasiun A berkaitan dengan kemampuan infiltrasi dan menahan air yang rendah. Laju infiltrasi tanah pada Mangrove Bedul tergolong tinggi yang dipengaruhi juga oleh kemantapan agregat tanah (Juarti, 2004: 30). Laju infiltrasi yang tinggi pada stasiun A dipengaruhi pula oleh tekstur tanah pasir berlempung.

Bahan organik berkaitan dengan tekstur tanah. Ketersediaan nitrogen dan phosphor di dalam tanah dipengaruhi oleh tekstur tanah. Tekstur tanah liat memiliki persentase nitrogen dan phosphor yang tertinggi dalam tanah. Tekstur tanah pada stasiun $\mathrm{B}$ dan $\mathrm{C}$ yang merupakan lempung berpasir dan liat memiliki kadar nigrogen dan phosphor yang lebih tinggi daripada tekstur tanah pasir berlempung pada stasiun A.

Kondisi tekstur tanah permukaan pada masing-masing stasiun pengamatan berbeda. Pada stasiun A komposisi tanah tergolong pasir berlempung. Kondisi tekstur tanah yang pasir berlempung memiliki nilai skor 2 (cukup sesuai). Pada kegiatan ekowisata yang melalukan pengamatan langsung pada vegetasi, tekstur pasir berlempung tidak berbahaya apabila berjalan kaki dalam kegiatan observasi langsung.

Tekstur tanah pada stasiun B adalah lempung berpasir. Tekstur lempung 
Bigharta Bekti Susetyo, Sudarno Herlambang, I Komang Astina. Analisis Evaluasi Kesesuainan Lahan Ekowisata Blok Mangrove Bedul Kabupaten Banyuwangi

berpasir memiliki skor 3 (sangat sesuai). Tekstur lempung berpasir cenderung lebih konsisten dan tidak membahayakan bila terdapat ekowisatawan yang melakukan observasi langsung terhadap ekosistem mangrove. Tanah berpasir memiliki laju infiltrasi yang tinggi, sehingga faktor erosi dapat diabaikan (Juarti, 2004: 28).

Kondisi tekstur tanah permukaan pada stasiun $\mathrm{C}$ tergolong pada tanah liat. Tekstur tanah liat pada stasiun C skor yang dimiliki 1 (sesuai bersyarat). Tekstur tanah liat membahayakan ekowisatawan minat khusus yang melakukan observasi langsung pada vegetasi dan biota ekosistem mangrove. Tekstur tanah liat cenderung selalu basah dan mampu menyimpan air. Tekstur tanah liat tahan akan erosi karena adanya gaya kosehi yang tinggi yang mengikat antar partikel air (Juarti, 2004: 28).

Penggunaan lahan di Ekowisata Blok Mangrove berhubungan dengan tutupan lahan vegetasi mangrove sungai dan muara. Data kondisi mangrove Bedul diperoleh dari pengukuran dan observasi. Pada setiap stasiun pengukuran dan observasi menggunakan tiga plot. Metode plot transek dan garis dibuat untuk menilai kerapatan, keanekaragaman jenis, ketebalan, kondisi pasang surut dan biota (Yulianda, 2007).

Pada stasiun A terdapat dominasi vegetasi Rhizopora mucronata, dan
Lumnitcera racemosa serta Ceriops sp. Nilai kerapatan vegetasi mangrove stasiun A adalah 31, dengan rerata 13 vegetasi Lumnitcera racemosa dalam satu plot. Pada stasiun B terdapat dominasi Avecennia, Rhizopora, Brugruiera, dan Ceriops sp. Nilai kerapatan vegetasi mangrove stasiun $\mathrm{B}$ adalah 23, dengan rerata 7 vegetasi Ceriops tagal dan Ceriops decandra. Pada stasiun C rerata 8 vegetasi Soneratia alba dalam setiap plot.

Kerapatan rata-rata mangrove pada tiga stasiun penelitian berkisar 21-31 jenis/100m². Menurut Yulianda (2007), kerapatan mangrove yang sangat sesuai yang diusahakan untuk ekowisata berkisar $15-25$ jenis $/ 100 \mathrm{~m}^{2}$. Kerapatan mangrove pada stasiun pertama sampai ketiga tidak berbeda jauh. Tegakan vegetasi mangrove pada stasiun $\mathrm{A}$ dan $\mathrm{B}$ tidak didominasi oleh tegakan pohon tetapi oleh vegetasi tingkat pancang dan semai. Tegakan pohon banyak dijumpai pada stasiun $\mathrm{C}$ dengan akar napas yang menjalar.

Keanekaragaman jenis vegetasi mangrove berperan dalam meningkatkan nilai indeks kesesuaian ekowisata. Pada stasiun penelitian ditemukan beberapa jenis vegetasi mangrove. Berikut jenis vegetasi mangrove pada beberapa stasiun pengukuran: 
Tabel 4 Jenis Vegetasi Mangrove Bedul

\begin{tabular}{llllll}
\hline No & NamaJenisVegetasi & NamaLokal & Stasiun & \\
\cline { 4 - 6 } & & & Stasiun 1 & Stasiun 2 & Stasiun 3 \\
\hline 1. & Avecennia alba & Api-api & 1 & 8 & - \\
2. & Avecenniaofficinalis & Api-apiputeh & 2 & - & - \\
3. & Rhizoporamucronata & Bakau & 12 & 8 & 17 \\
4. & Rhizoporaapiculata & Bakau & 3 & 2 & 21 \\
5. & Bruguieragymnorriza & Tanjang & 5 & 11 & - \\
6. & Lumnitceraracemosa & - & 38 & - & - \\
7. & Soneratia alba & Perpat & - & - & 24 \\
8. & Ceriopstagal & Tagal & 15 & 21 & - \\
9. & Ceriopsdecandra & Tingi & 16 & 20 & - \\
\hline
\end{tabular}

Keanekaragaman vegetasi Mangrove Bedul yang terdapat pada stasiun pengamatan berjumlah sembilan jenis. Keanekaragaman vegetasi Mangrove Bedul memiliki nama-nama lokal dalam penyebutannya. Penilaian keragaman vegetasi Mangrove Bedul tergolong tinggi karena mempunyai vegetasi lebih dari lima jenis (Yulianda, 2007).

Ketebalan vegetasi mangrove sempadan sungai merupakan jarak antara vegetasi tepi sungai sampai vegetasi mangrove terdepan (Tuwo, 2011).

Mengukur ketebalan mangrove di sempadan sungai bida diukur dengan menarik garis tegak lurus tepi sungai sampai vegetasi mangrove terdepan. Mengukur ketebalan mangrove bisa dilakukan dengan aplikasi ArcGIS 10.1 melalui titik koordinat yang sebelumnya sudah tercatat di GPS. Berikut ketebalan vegetasi mangrove pada masing-masing stasiun pengukuran:

\section{Tabel 5 Ketebalan Mangrove Bedul}

\begin{tabular}{lll}
\hline Stasiun & TitikKoordinat & Kebebalan Mangrove \\
\hline Stasiun A & $08^{0} 35^{\prime} 29,468^{\prime}$ LS $114^{0} 15^{\prime} 47,208^{\prime \prime}$ BT & 284,4 meter \\
Stasiun B & $08^{0} 35^{\prime} 33,537^{\prime}$ LS $114^{0} 15^{\prime} 58,23^{\prime \prime} \mathrm{BT}$ & 272,5 meter \\
Stasiun C & $08^{0} 35^{\prime} 49,599^{\prime}$ LS $114^{0} 16^{\prime} 22,329^{\prime \prime}$ BT & 252,01 meter \\
\hline
\end{tabular}

Kondisi ketebalan Mangrove Bedul termasuk dalam kategori cukup sesuai (Yulianda, 2007). Ketebalan mangrove dalam kegiatan ekowisata berpengaruh dalam kegiatan ekowisata. Beberapa kegiatan dalam ekowisata yang memiliki hubungan dengan ketebalan mangrove adalah trecking, bird watching dan kegiatan konservasi.

Kondisi pasang surut merupakan kondisi yang memperhatikan pola pasang surut pada daerah penilitan. Menurut
Wyrtki perairan selatan Pulau Jawa tergolong dalam pasang surut campuran condong harian ganda (Nontji,1987: 97). Pengetahuan akan pola pasang surut diperlukan dalam ekowisata mangrove yang terpengaruh oleh pasang surut.

Selisih pasang dan surut merupakan salah satu kondisi yang tidak dapat dipisahkan dari kesesuaian lahan ekowisata mangrove (Yulianda, 2007). Pada daerah penelitian, pola surut terjadi pada jam sepuluh pagi dan berangsur 
Bigharta Bekti Susetyo, Sudarno Herlambang, I Komang Astina. Analisis Evaluasi Kesesuainan Lahan Ekowisata Blok Mangrove Bedul Kabupaten Banyuwangi

pasang pada jam empat sore. Pasang tertinggi pada perairan muara Sungai Segoro Anakan sebesar 2,3 meter dan surut terendah 0,3 meter (Resort Bedul, 2015). Selisih pasang surut pada perairan Mangrove Bedul sebesar 2 meter. Pada kegiatan observasi setiap stasiun, dilakukan pengamatan terhadap jenis bi- ota. Pengamatan jenis biota menggunakan instrumen pengisian.

Vegetasi mangrove yang tumbuh di endapan sempadan sungai tidak terlepas dari biota yang ada. Pengamatan biota Mangrove Bedul dilakukan pada siang hari sampai sore hari. Berikut jenis biota yang terdapat pada Mangrove Bedul:

Tabel 6 Sebaran Jenis Biota Mangrove Bedul Setiap Stasiun Penelitian

\begin{tabular}{llll}
\hline No & Stasiun & JenisBioita & Spesies \\
\hline 1. & Ikan & IkanBedul, Ikan Kecil, \\
& Crustacea & Kepiting \\
& Bivalva & Kerang-kerangan \\
& Reptil & - \\
& Aves & Burung-burungpantai \\
& Mammalia & - \\
2. & Ikan & \\
& Stasiun B & Crustacea & IkanBedul, Ikankecil \\
& Bivalva & Kepiting \\
& Reptil & Kerang-kerangan \\
& Aves & - \\
& Mammalia & - \\
& & - \\
& Stasiun C & Crustacea & Ikan \\
& Bivalva & Kepiting \\
& Reptil & - \\
& Aves & Biawak \\
& Mammalia & Burung \\
& & Keraekorpanjang \\
\hline
\end{tabular}

Objek biota pada indeks keseuaian ekowisata mangrove meliputi pisces, crustacea, bivalva, reptil dan mamalia (Yulianda, 2007). Banyaknya jenis biota yang berada pada stasiun penelitian dijadika dasar penilaian biota. Pada stasiun penelitian dijumpai Ikan Bedul, ikan kecil, kepiting, reptil, burung pantai dan kera ekor panjang.

\section{PENUTUP}

\section{Kesimpulan}

Berdasarkan evaluasi kesesuaian lahan ekowisata dapat disimpulkan bahwa kesesuaian lahan Ekowisata Blok Mangrove Bedul mempunyai kriteria sangat sesuai dan cukup sesuai. Kesesuaian lahan dengan penggunaan lahan di Ekowisata Blok Mangrove Bedul merupakan ekosistem mangrove tipe sungai dan muara. Dominasi vegetasi di Ekowisata Blok Mangrove Bedul Ceriops 
sp, Rhizopora, Lumnitcera, Avecennia, Brugruiera, dan Sonneratia.

\section{Saran}

Penelitian ini menghasilkan saran berhubungan dengan tingkat kesesuaian lahan Ekowisata Mangrove Bedul. Saransaran diberikan untuk pengelola dan dinas terkait. Pengelola Ekowisata Mangrove Bedul diharapkan untuk meninggkatkan daya dukung lahan yang masih bisa untuk ditingkatkan. Faktor akses terhadap air bersih untuk ekowisatawan masih sulit. Keterjangkauan air bersih menjadi kekurangan pada tiga stasiun pengukuran yang masih bisa untuk diupayakan lebih baik. Pemetaan terhadap zonasi jenis mangrove diperlukan untuk informasi ekowisata Mangrove Bedul. Pengelola Ekowisata Mangrove Bedul diharapkan meningkatkan perannya dalam edukasi vegetasi mangrove karena memiliki keragaman jenis, kerapatan dan lebar mangrove yang sesuai.

\section{DAFTAR RUJUKAN}

Arief, Arifin. 2001. Hutan \& Kehutanan. Penerbit Kanisius: Yogyakarta.

Fahriansyah dan Yoeswaty Deasy. 2012. Pembangunan Ekowisata di Kecamatan Tanjung Balai Asahan, Sumatera Utara: Faktor Ekologis Hutan Mangrove. Jurnal Ilmu dan Teknologi Kelautan Tropis, 4 (2): 346-359.

Foth, Henry D. 1984. Fundamentals of Soil Science. John Wiley \& Sons Inc: New York.

Jamulya dan Yunianto, Tukidal. 1991. Kursus: Evaluasi Sumberdaya Lahan (Tanah dan Survey Tanah). Yogyakarta: UGM Press.
Juarti. 2004. Konservasi Lahan \& Air. Malang: UM PRESS.

KEPMEN LH No. 51 Tahun 2004. (Online), (http://www.ppkkp3k.kpp.go.id/ver2/media/downlo ad/RE_keputusan-menteri-negaralingkungan-hidup-nomor-51-tahun2004.pdf), diakses 12 Desember 2014.

Nontji, Anugerah. 1987. Laut-Laut Nusantara. Jakarta: Djambatan.

Nugroho, Iwan. 2011. Ekowisata dan Pembangunan Berkelanjutan. Yogyakarta: Pustaka Pelajar.

Pangesti, Tri. 2007. Modul Identifikasi Objek Wisata Alam. (online) (www.researchengines.com/tripang esti6-07.html), diakses pada 12 Desember 2014.

Sitorus, Santun P. 1985. Evaluasi Sumberdaya Lahan. Bandung: Tarsito

Tangketasik, dkk. 2012. Kadar Bahan Organik Tanah pada Sawah dan Tegalan di Bali serta Hubungannya dengan Tekstur Tanah. Agrotrop 2 (2):101-107.

Tuwo, Ambo. 2011. Pengelolaan Ekowisata Pesisir dan Laut (Pendekatan Ekologi SosialEkonomi, Kelembagaan dan Sarana Wilayah). Surabaya: Brilian Internasional.

Widiyanto dan Dibyosaputro, Suprapto. 1991. Kursus: Evaluasi Sumber daya Lahan (Latihan ESL untuk Kepariwisataan). Yogyakarta: UGM Press.

Yulianda, F. 2007. Ekowisata Bahari sebagai Alternatif Pemanfaatan Sumberdaya Pesisir Berbasis Konservasi. Disampaikan pada Seminar Sains 21 Februari 2007.Bogor: Departemen MSP. FPIK. IPB. 